\title{
A Forward Silicon Strip System for the ATLAS HL-LHC Upgrade
}

9th International Conference on Radiation Effects on Semiconductor Materials Detectors and Devices

9-12 October 2012, Florence, Italy

Sven Wonsak, University of Freiburg On behalf of the ATLAS Endcap Tracker Upgrade Group

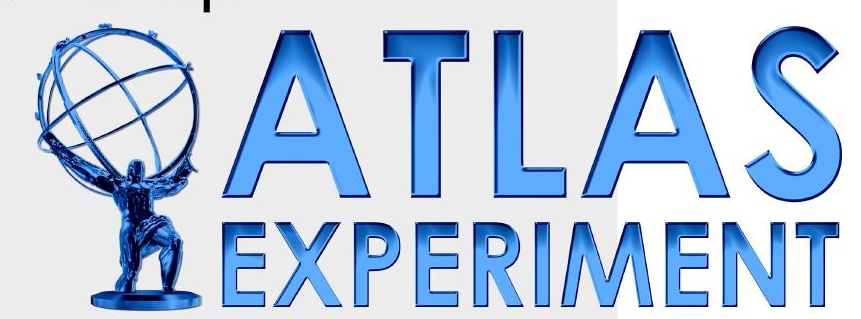




\section{ATLAS Endcap Tracker Upgrade Group}

Malik Aliev', Dario Arizac ${ }^{c}$, Tom Barberd, Victor Benitez ${ }^{\mathrm{a}}$, Jose Bernabeu $^{\mathrm{e}}$, Ingo Bloch ${ }^{\mathrm{b}}$, Richard Brenner ${ }^{\mathrm{f}}$, Conrad Friedrich ${ }^{\mathrm{b}}$, Nico Görrissen ${ }^{\mathrm{b}}$, Ingrid Gregor ${ }^{\mathrm{b}}$, Marc Hauser ${ }^{\mathrm{d}}$, Susanne $K_{\text {Kühn }}{ }^{d}$, Carlos Lacasta ${ }^{\mathrm{e}}$, Heiko Lacker ${ }^{\mathrm{c}}$, Besnik Lecini ${ }^{\mathrm{d}}$, Kambiz Mahboubi $^{\mathrm{d}}$, Ricardo Marco ${ }^{\mathrm{e}}$, Ulrich Parzefalld ${ }^{\mathrm{d}}$, Volker Prahl ${ }^{\mathrm{b}}$, Laura Rehnisch ${ }^{c}$, David Santoyo ${ }^{\mathrm{e}}$, Urmila Soldevila ${ }^{\mathrm{e}}$, Marcel Stanitzki ${ }^{b}$, Miquel Ullan ${ }^{\mathrm{a}}$, Sven Wonsak ${ }^{\mathrm{d}}$

${ }^{a}$ CNM Barcelona, ${ }^{b}$ DESY, ${ }^{c}$ Humboldt University Berlin, d University Freiburg, e IFIC-Valencia (CSIC, UVEG), ${ }^{\dagger}$ Uppsala University
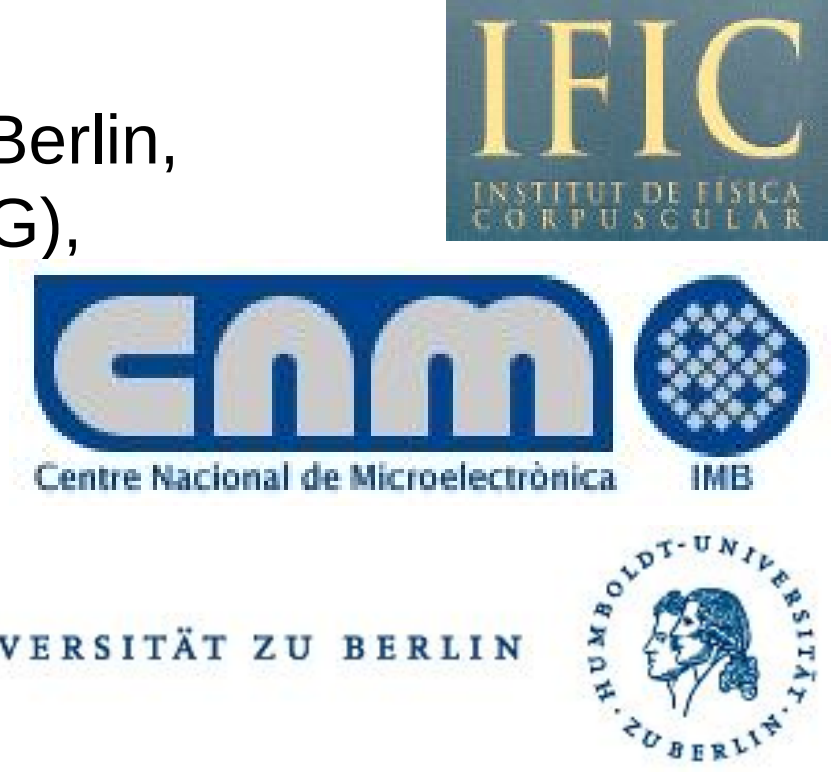


\section{Outline}

The ATLAS Endcap HL-LHC Upgrade

The Petalet Project

- Freiburg Hybrid Specification and Population

- Hybrid Test Results

- Module Building

" Summary / Outlook 


\section{ATLAS Endcap HL-LHC Upgrade}

- Inner Tracker (IT) needs upgrade for HLLHC

- Radiation damage of IT

- HL-LHC track density too high for current IT granularity

- New barrel integration concept: readout electronics glued directly on sensor, sensor glued to support structure

New IT will have:

- p-type sensors

- 5 barrel layers

- 6 endcap disks:

- Each disk has 32 "petals" (close to barrel stave design)

- Each petal has 2x9 sensors
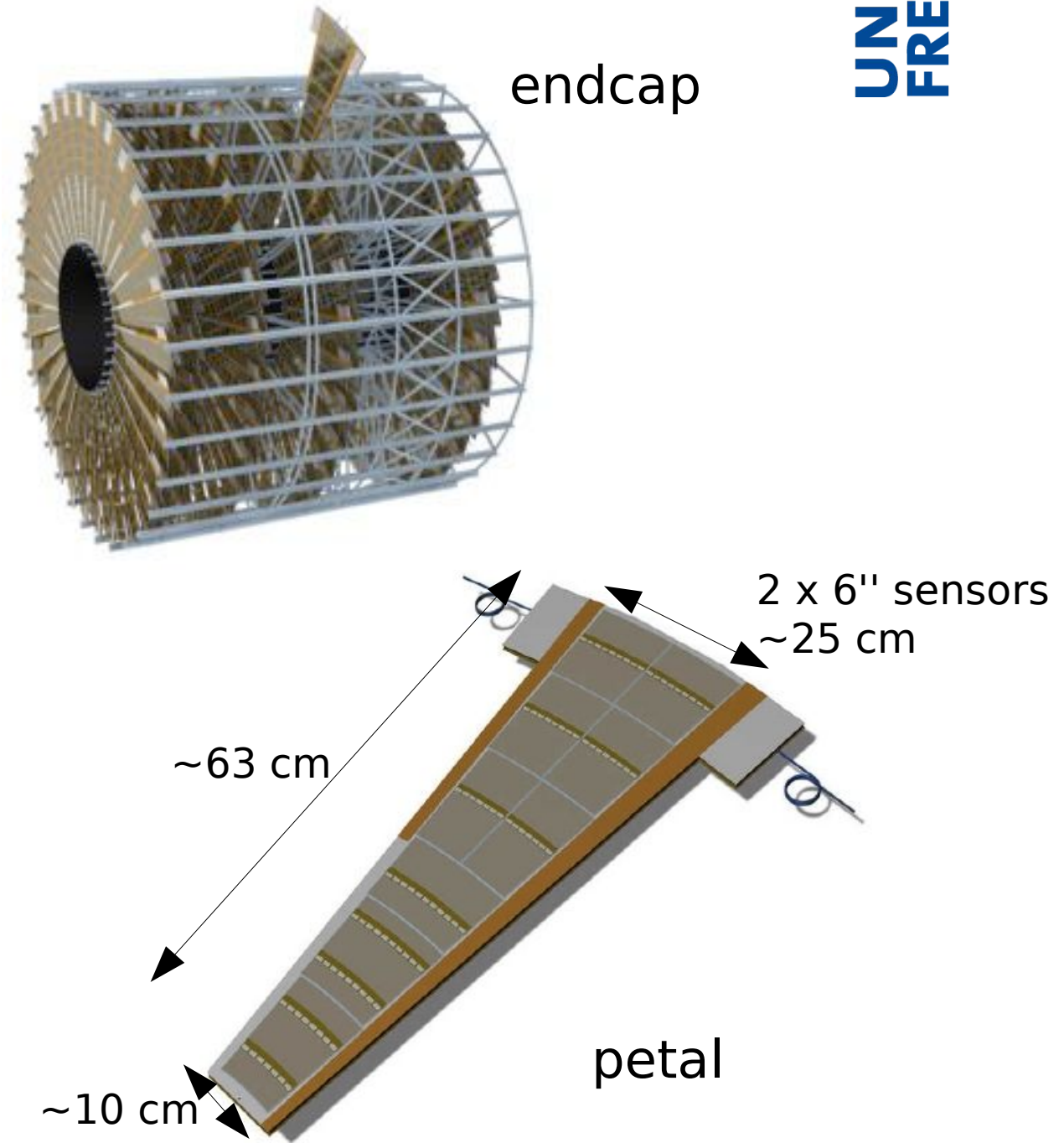

See also the talk "Upgrading the ATLAS Silicon Tracking of the HL-LHC" from Tom Barber 


\section{The Petalet Project}
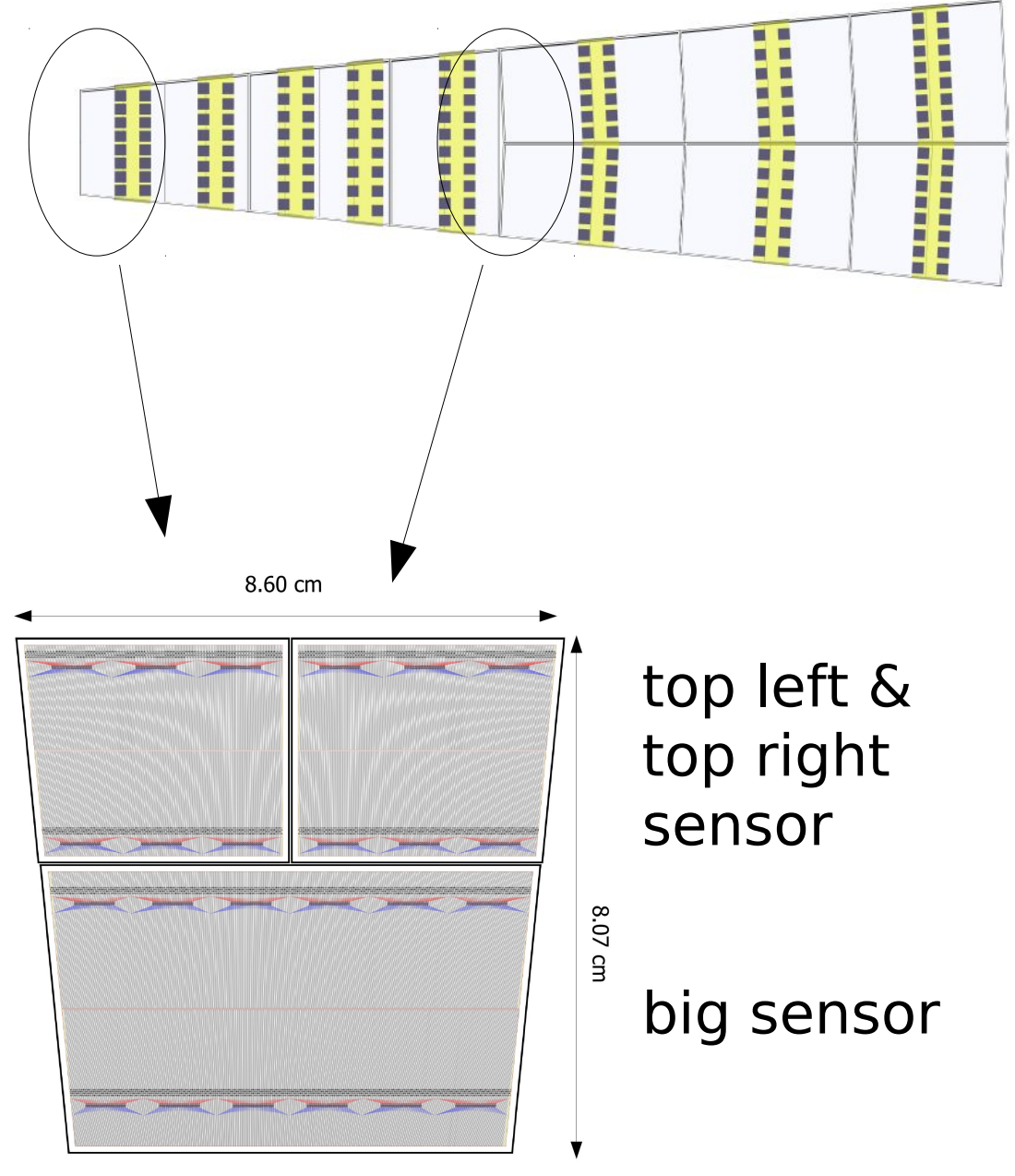

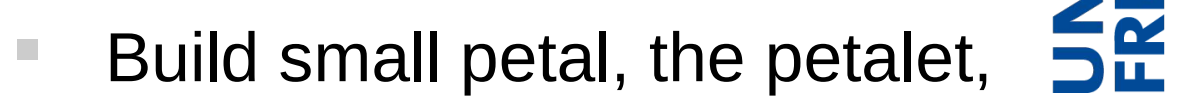
to concentrate on major subjects: innermost radius with smallest strip pitch and region where petal splits in 2 sensor columns

- Sensors are build at CNM
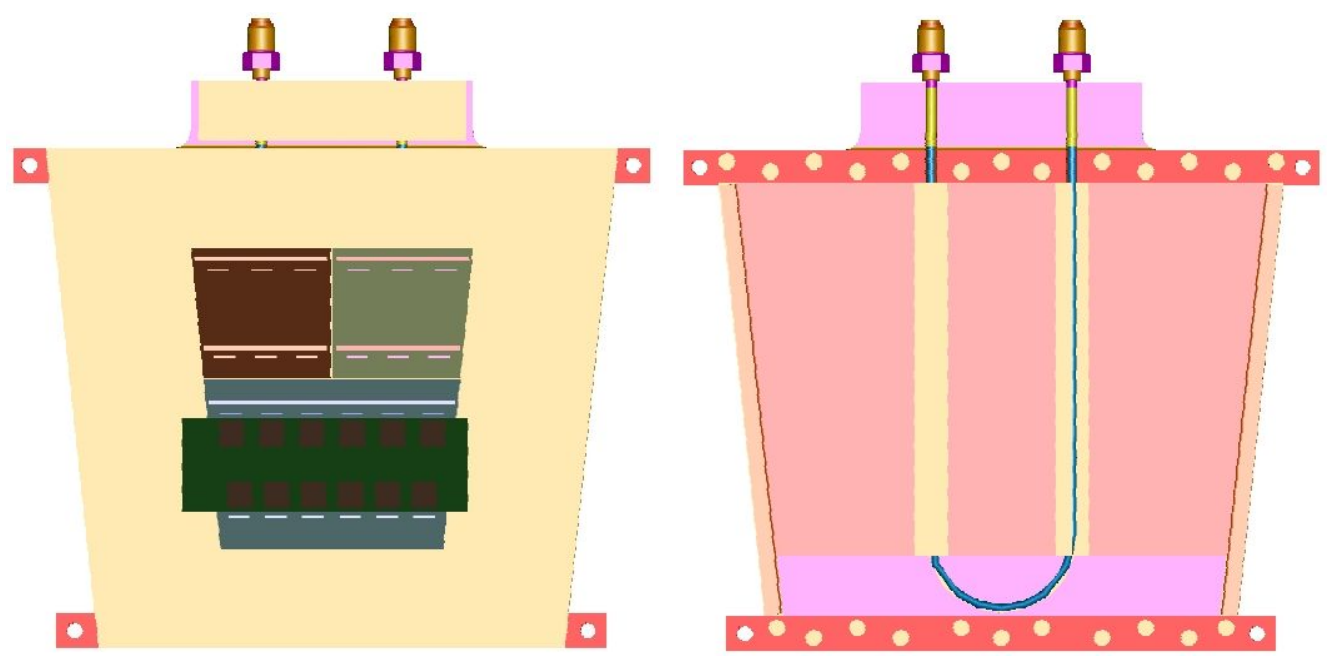

drawing of the petalet core 


\section{CNM Sensors for Petalet I}

" Design and production for 4" wafer

- Different strip pitch

- Implemented stereo angle (20mrad)

- Double metal layer to implement embedded fanins which match with the bondpads of the readout chips to avoid large bond angles

- $\quad$ First run without embedded fanins shipped begin of May

- First run with double metal mini sensors show differences to single metal layer $\rightarrow$ under investigation

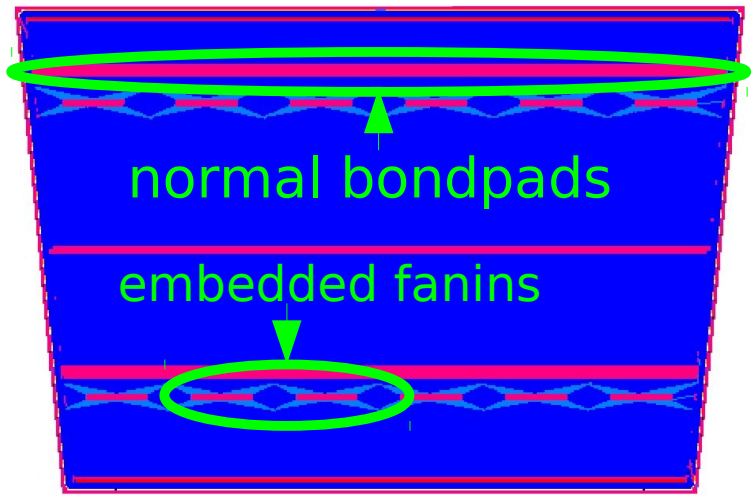




\section{CNM Sensors for Petalet II}

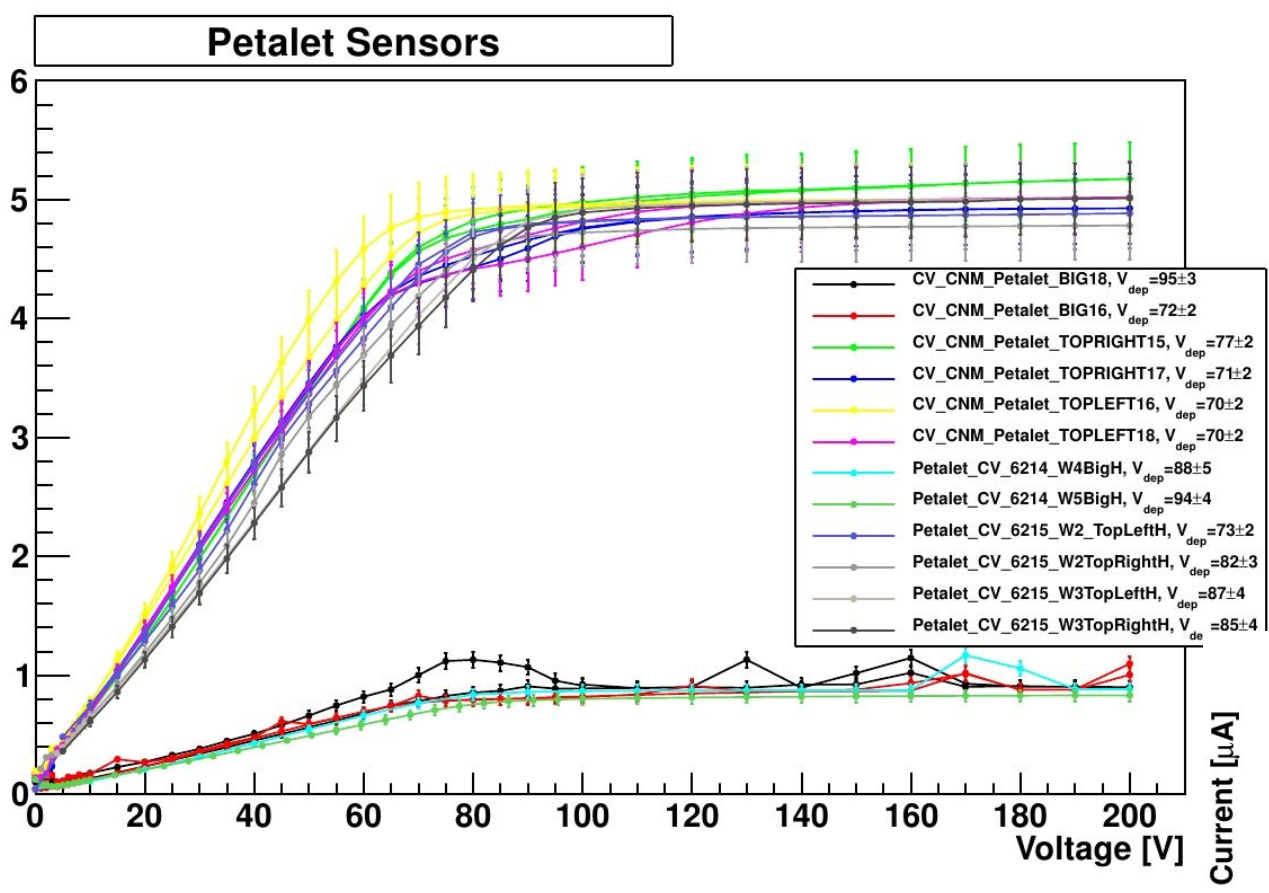

- CV and IV measurements of all sensors in Freiburg (for 2 full petalets)

- Results show good agreement with measurements from CNM

- Depletion Voltage:

$70 \mathrm{~V}-95 \mathrm{~V}$

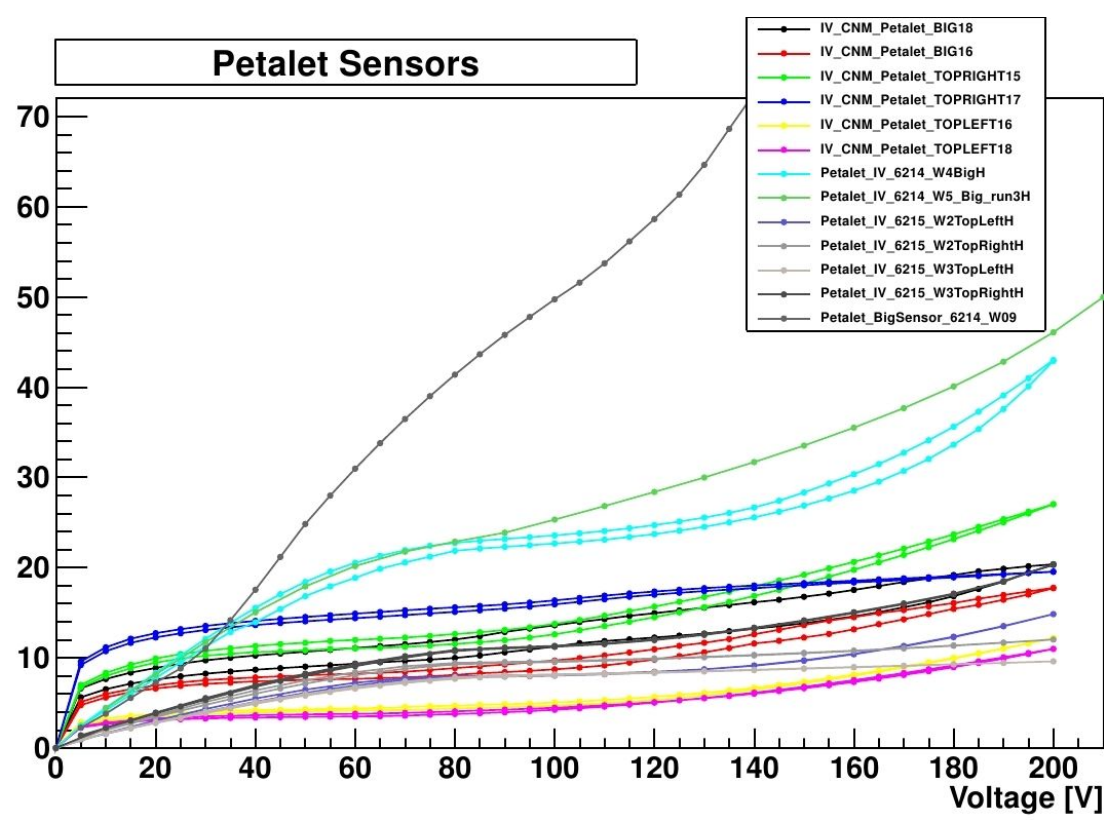




\section{Two Petalet Versions}

backside

frontside

power

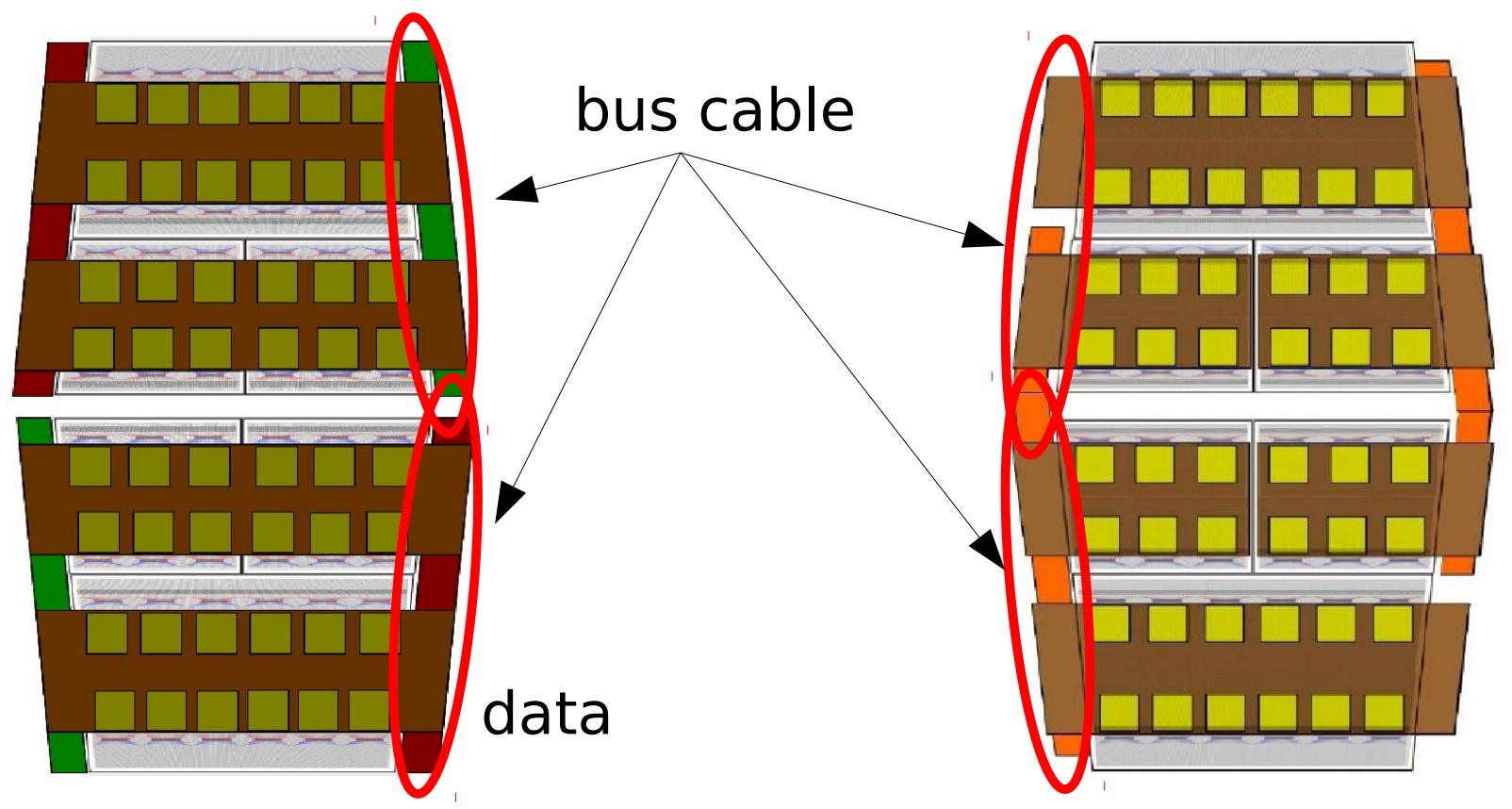

"The Bear":

- Power and Data on two different sides/bus cables

- One single hybrid for top sensors
"Lamb and Flag"

- Data and power on same side of bus cable

- Each sensor has its own hybrid 


\section{Petalet Bus Cable}

“Bear"

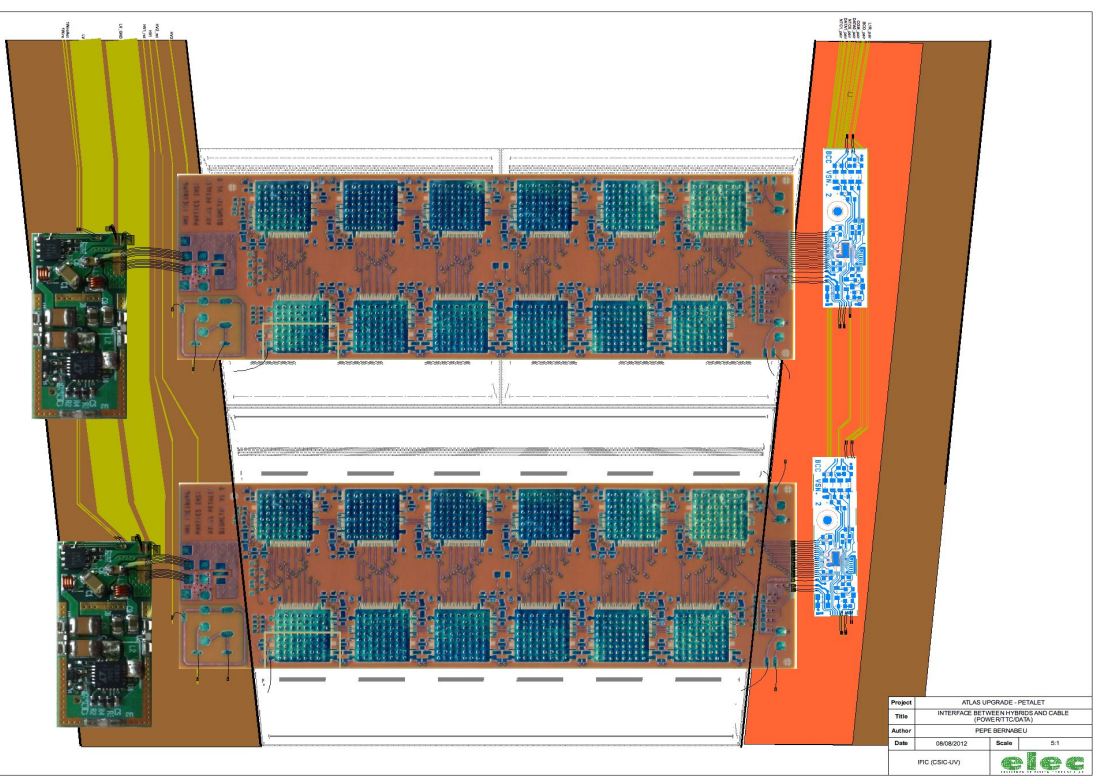

\section{“Lamb and Flag"}

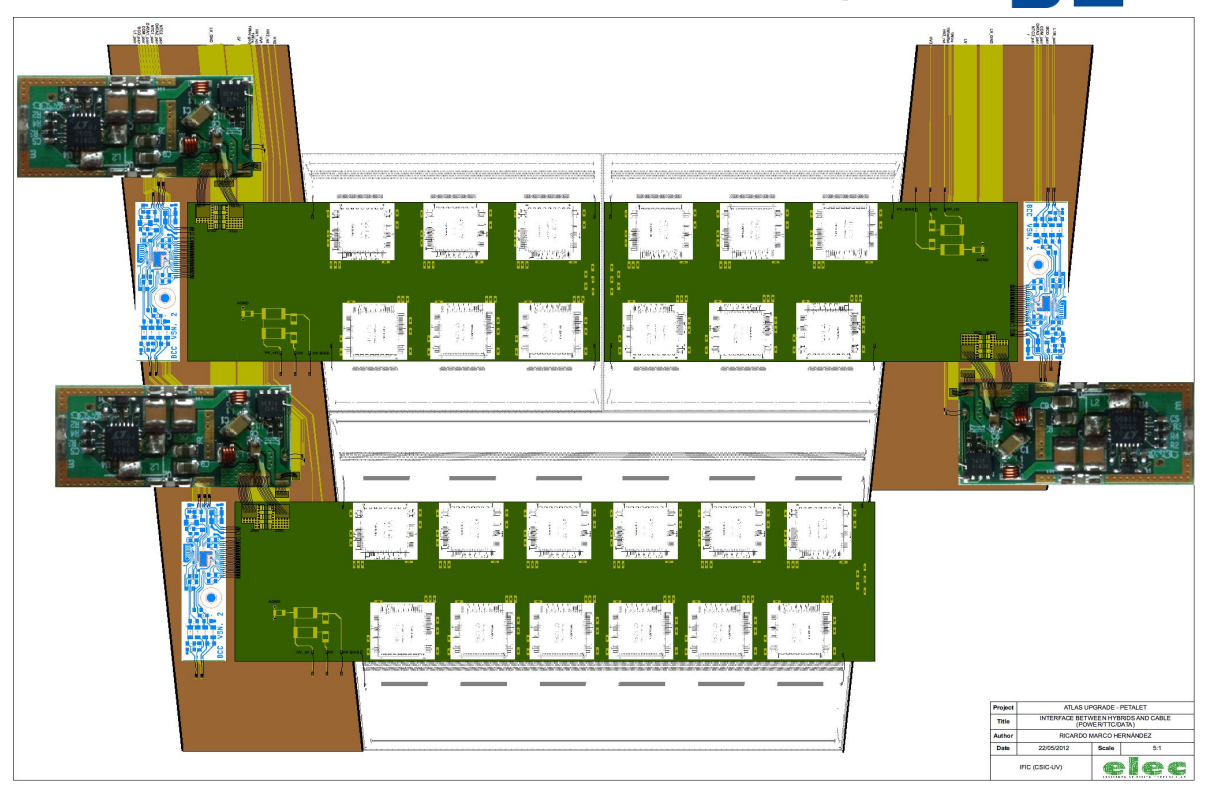

First design studies of the bus cable for both petalet versions shown were done

- Lamb and Flag: not so much space on the bus cable so that the DCDC converter is overhanging 


\section{Freiburg Hybrid}

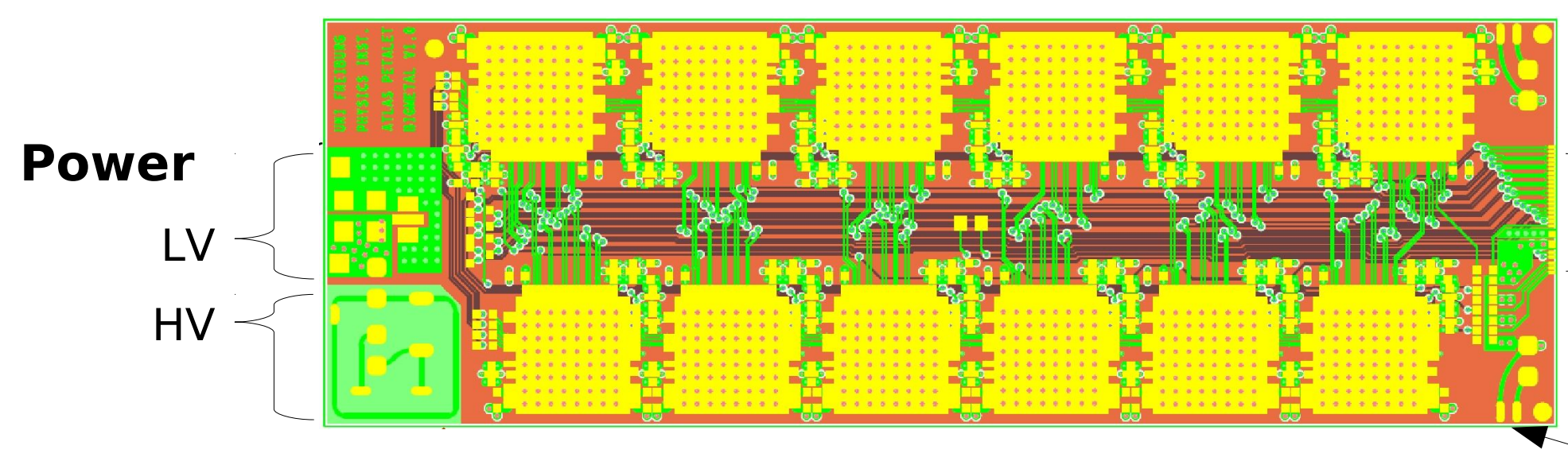

" Hybrid for "big" petalet sensor (Bear) produced

- Design at Freiburg

- 4-Layer Flex-PCB (85mm x 28mm)

- $100 \mu m$ track and gap

- Production and population of Surface Mounted Devices (resistors, capacitors) by German companies

- Received first batch begin of July this year 


\section{ASIC to Hybrid glueing}

- Use same method as for stave module building:

- ASICs placed in Chip Tray and picked up with Pickup Tool

- Silver epoxy glue spread on backside of ASICs with ASIC Glue Stencil

- ASICs glued on hybrid (placed on jig) with Pickup Tool

- Glue height is defined with fine thread screws on Pickup Tool

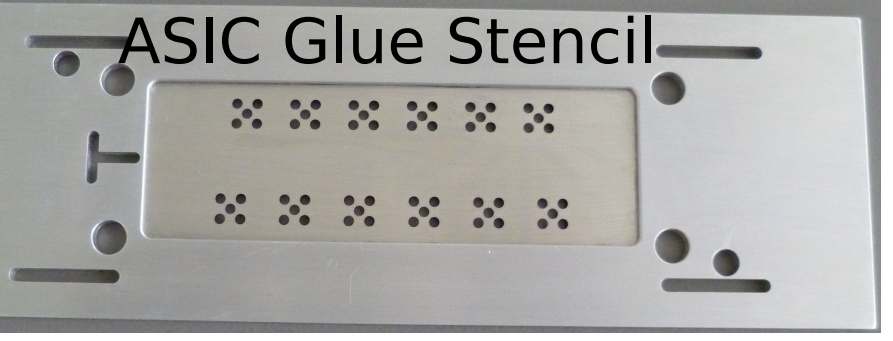

hybrid placed on jig

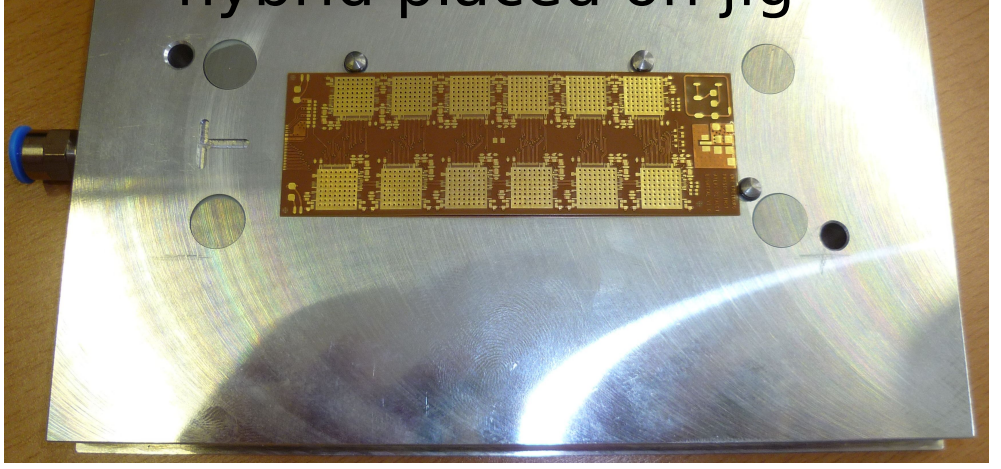

Pickup Tool

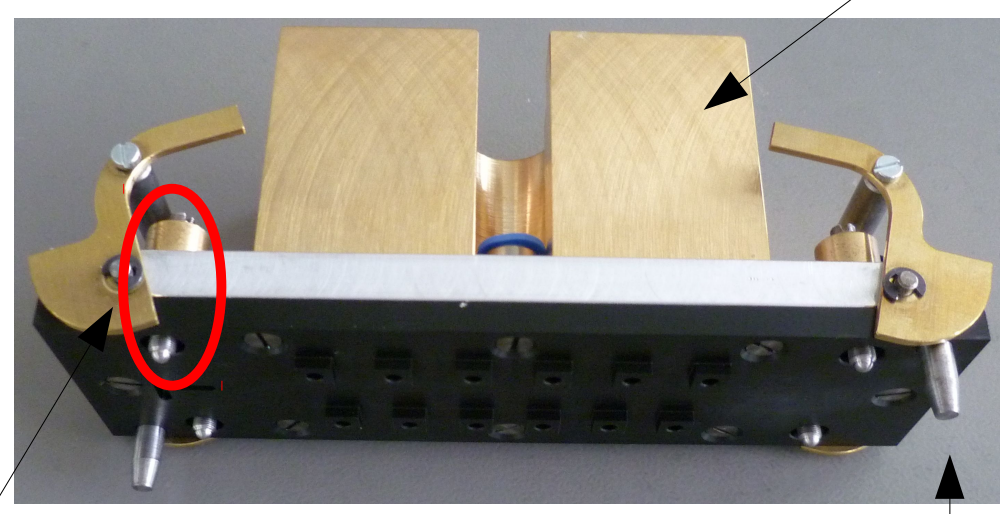

fine thread

screw positioning pin brass weight 


\section{Complete Hybrid}

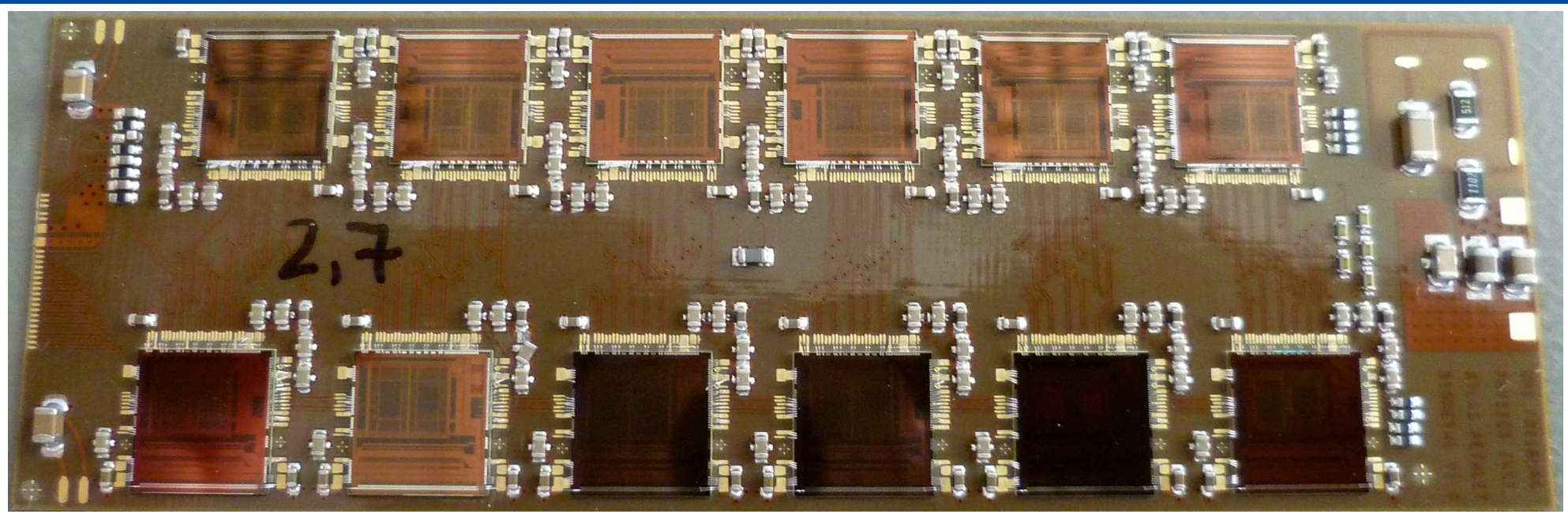

Planned glue height approximately $60 \mu \mathrm{m}$

- Glue dots compressed and no glue oozes out

- Measurements show good agreement

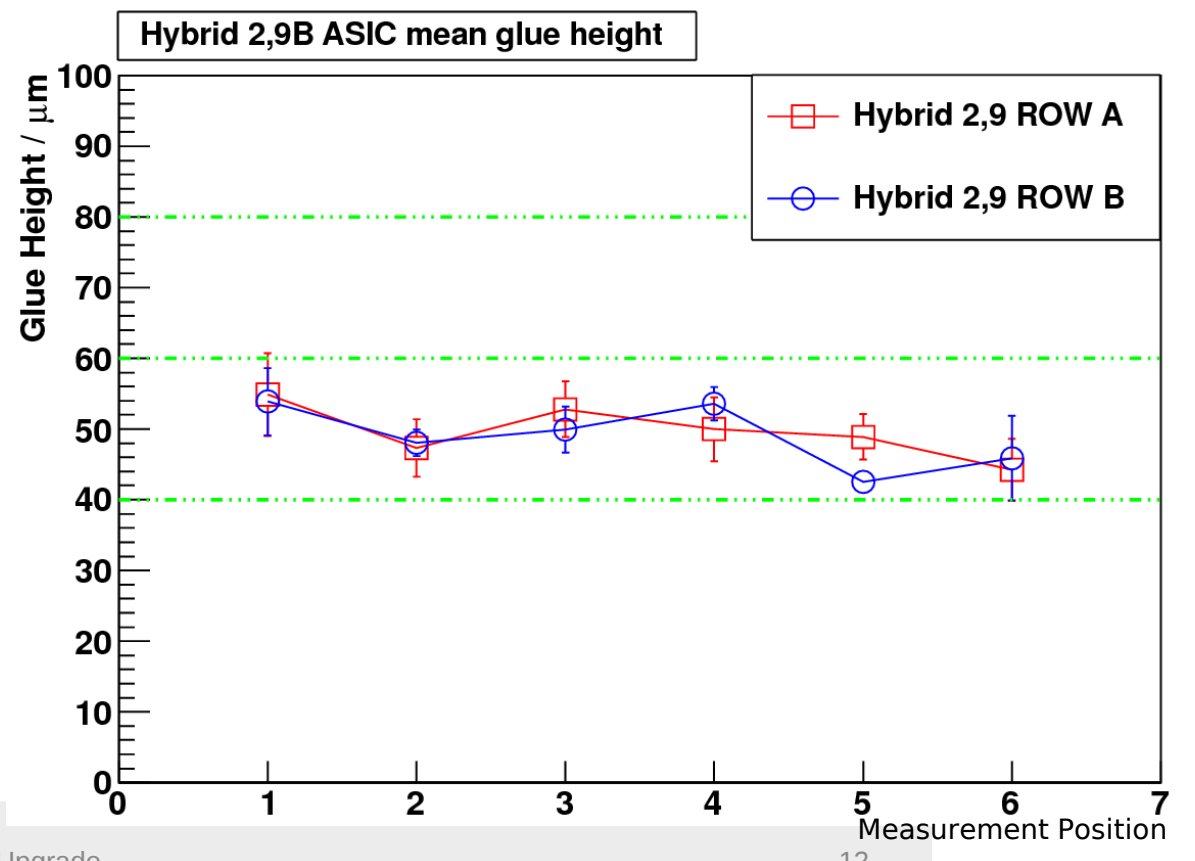




\section{Module Building}

- Sensor placed on Module Building Jig

- Use Pickup Tool to lift hybrid

- Glue spread on backside of hybrid with metal Hybrid Glue Stencil

- Hybrid glued on sensor

- Normal bond pads and embedded fanins have different radial locations, 2 alternative positions provided by brass inserts

Glue height defined by jig design (height difference between sensor backside and fine thread screws)

Module Building Jig

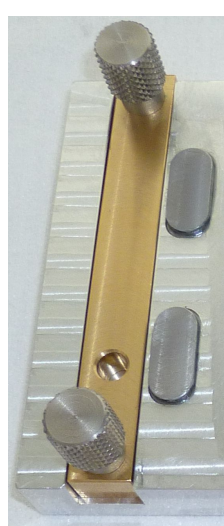

(1)

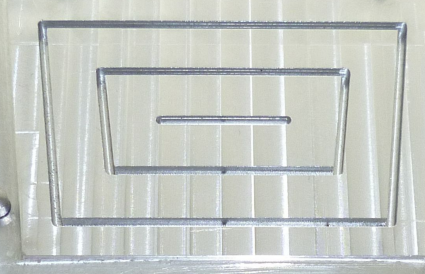

道

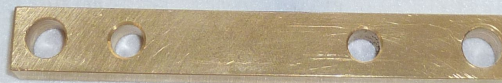

o. 0
9

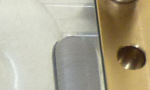

$\Delta$

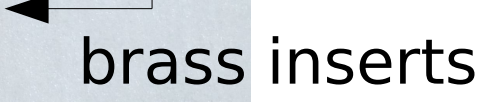

Hybrid Glue Stencil

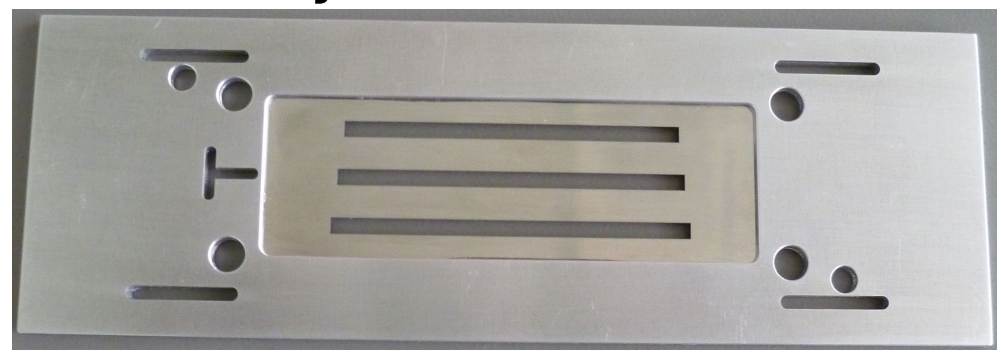

glue on hybrid backside

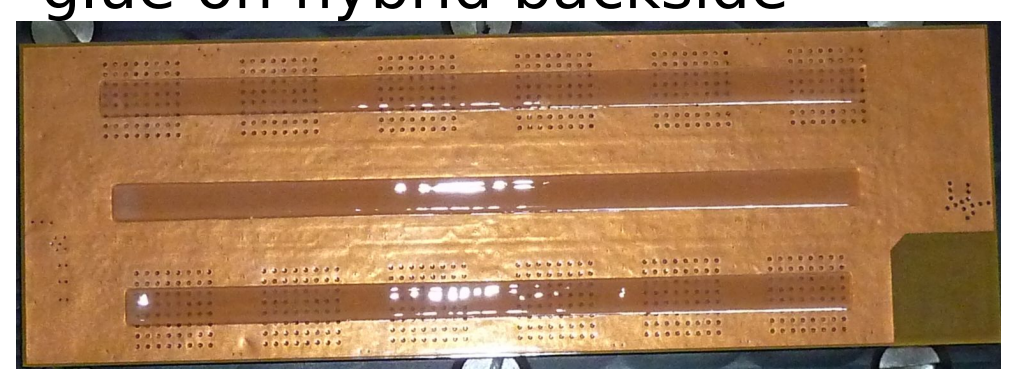




\section{Summary / Outlook}

- Single metal layer sensors produced, shipped and ready for usage, batch of sensors with two metal layers in production

" Hybrids for big sensor ("Bear" version) designed and produced

- Performance tests of singe hybrids excellent (Noise -380 ENC), tests for first module started

- Construction of top hybrid for "Bear" petalet started $\rightarrow$ planned completion date: early December

- Design of tools for new hybrid nearly finished, will start production soon

" Design of hybrids for "Lamb and Flag" version and the bus cable started

- Design of core nearly finished, will start construction with support from LBNL 
Thank you for your attention. 


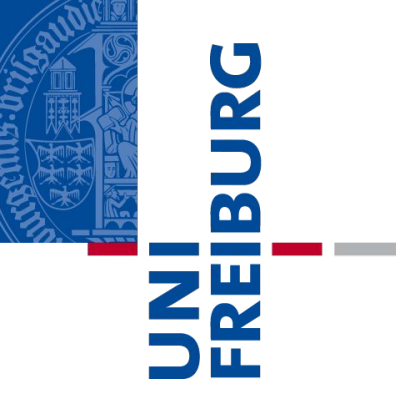

\section{Backup}




\section{Petalet Sensors / Wafer}
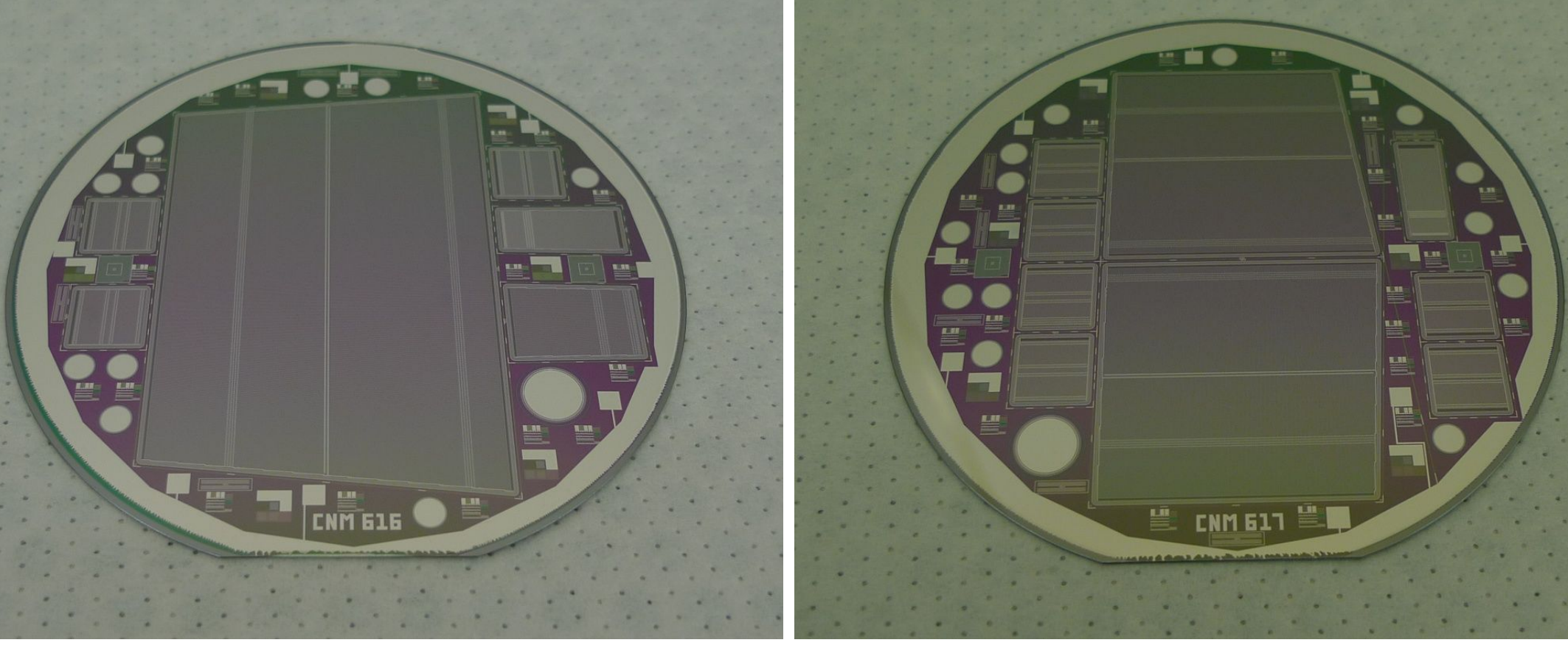

" Wafer with petalet sensors, produced by CNM 


\section{CNM IV Measurements}
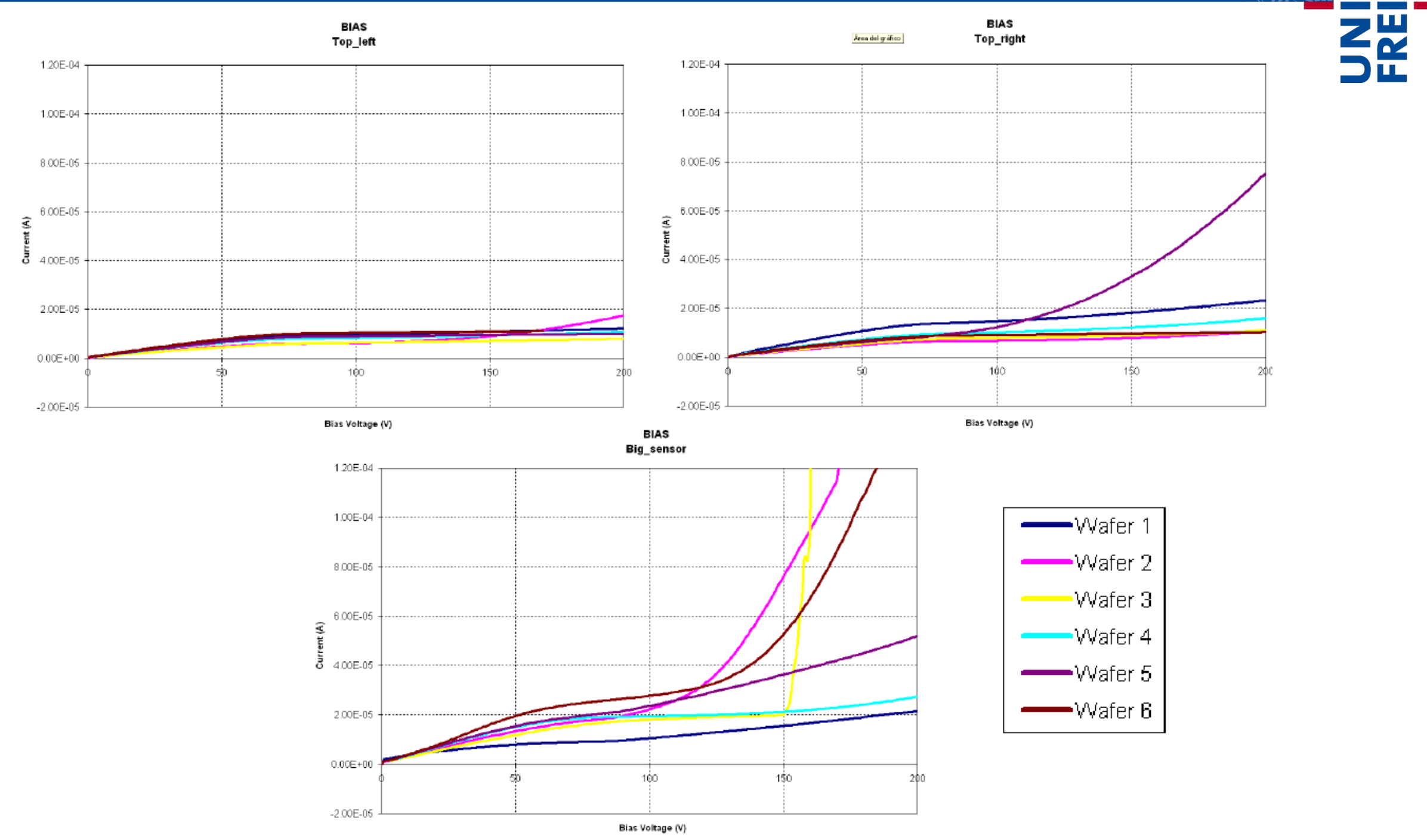


\section{CNM CV Measurements}

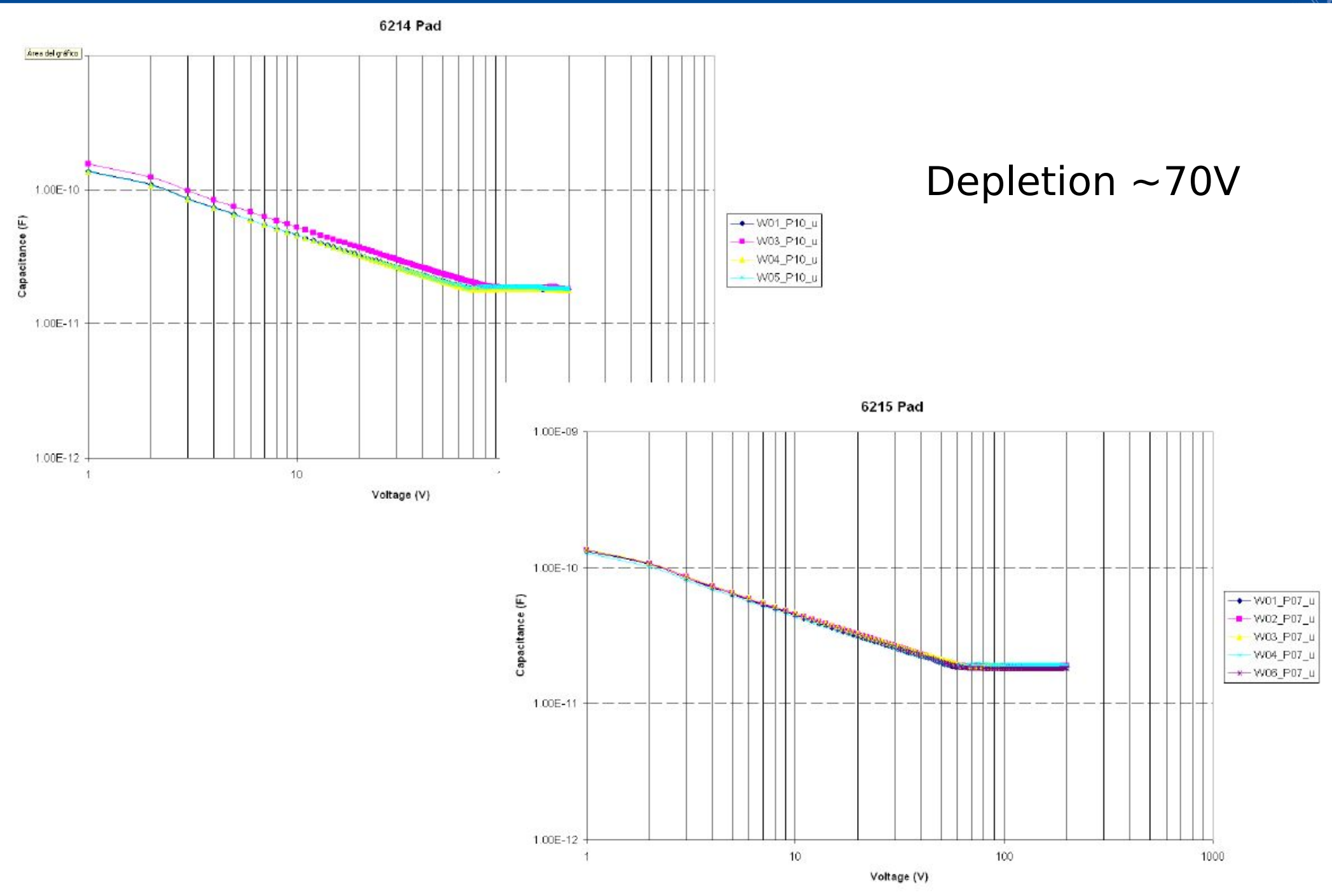




\section{HSIO Readout System}

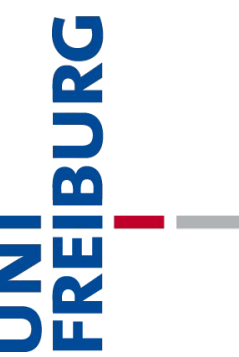

Test device in light tight box, flushed with nitrogen and mounted on a cooled test jig $\left(8^{\circ} \mathrm{C}\right)$

- HSIO: High Speed I/O with good Virtex FPGA

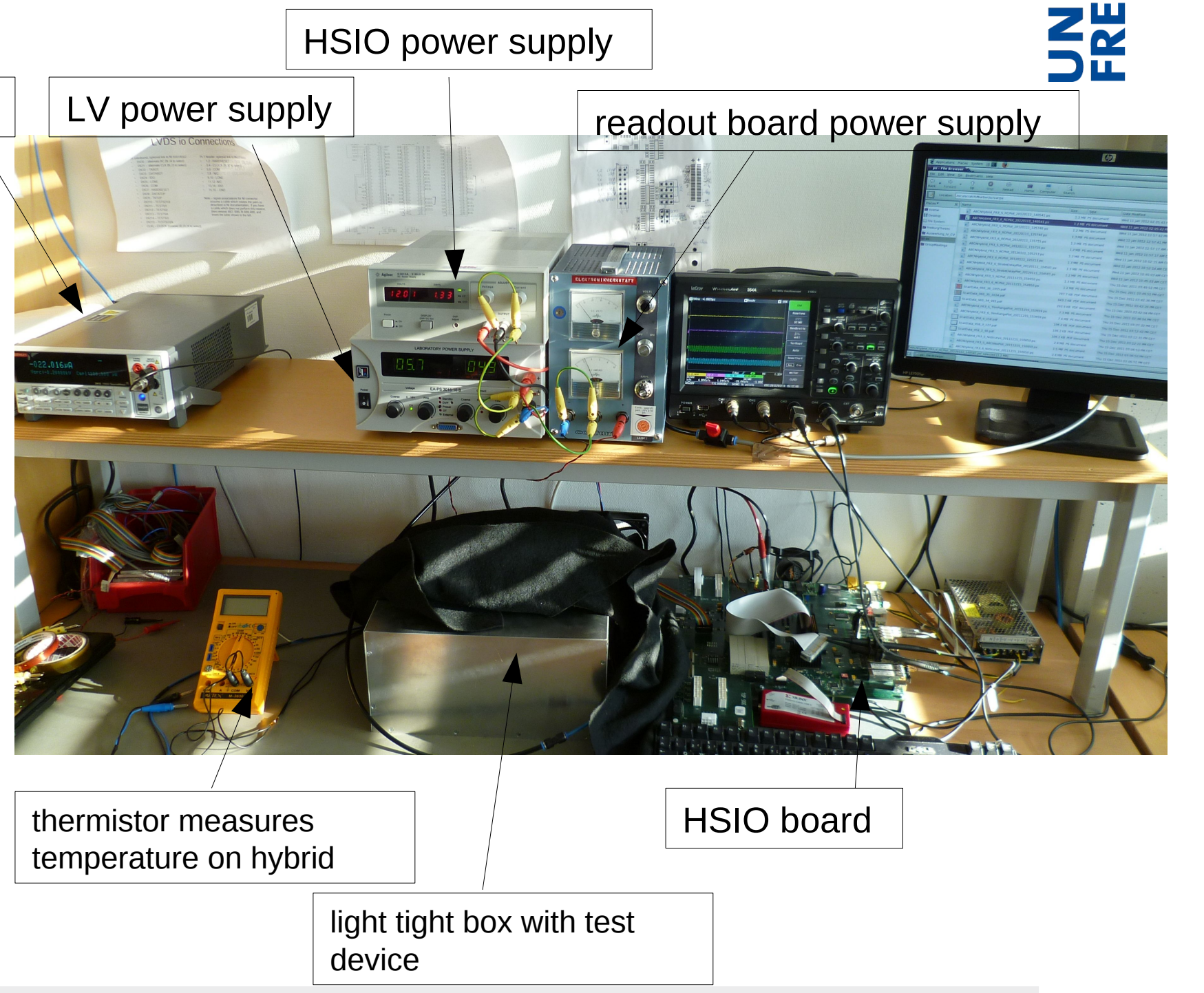




\section{Hybrid/Module Testing}

\section{Test hybrids with selfmade testframe}

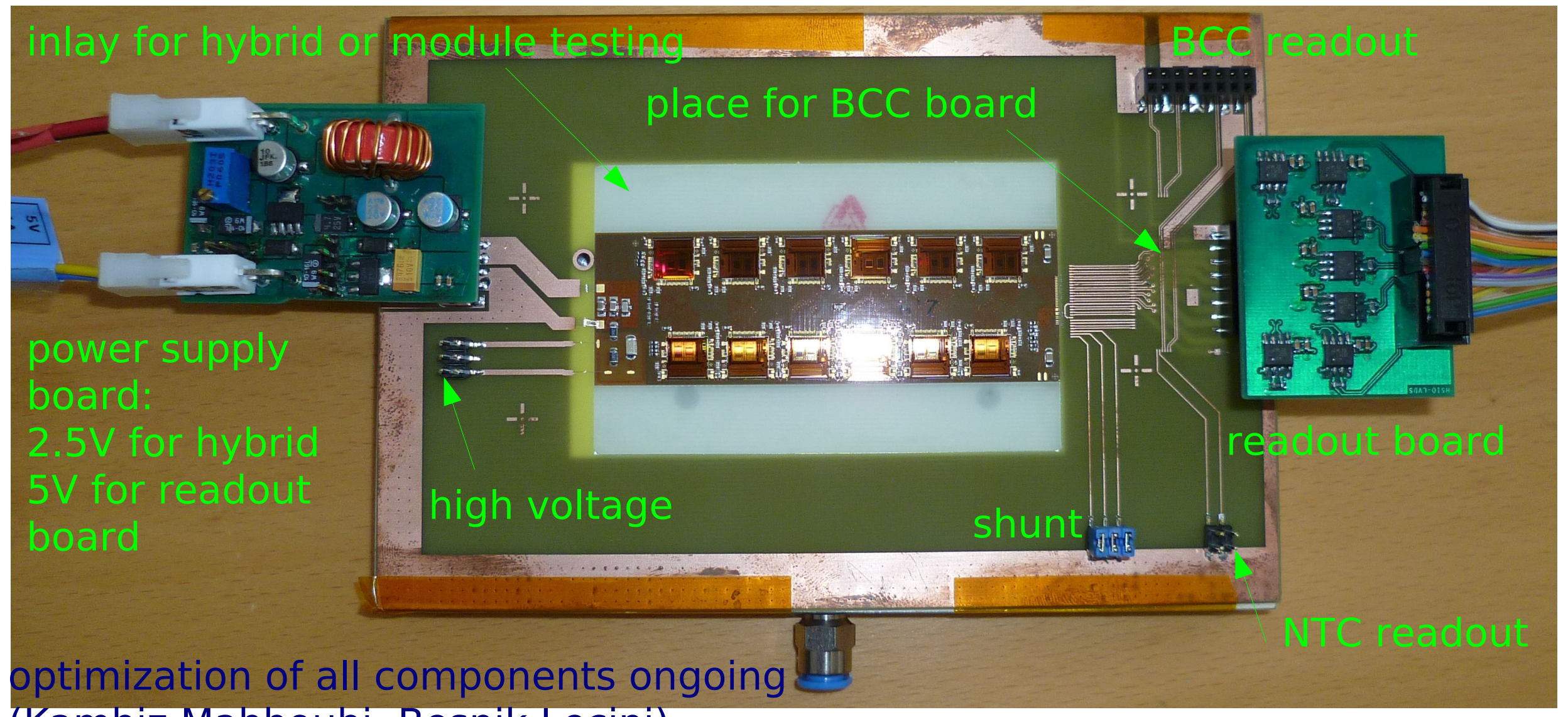

(Kambiz Mahboubi, Besnik Lecini) 


\section{Top Sensor - Bear Module Building}

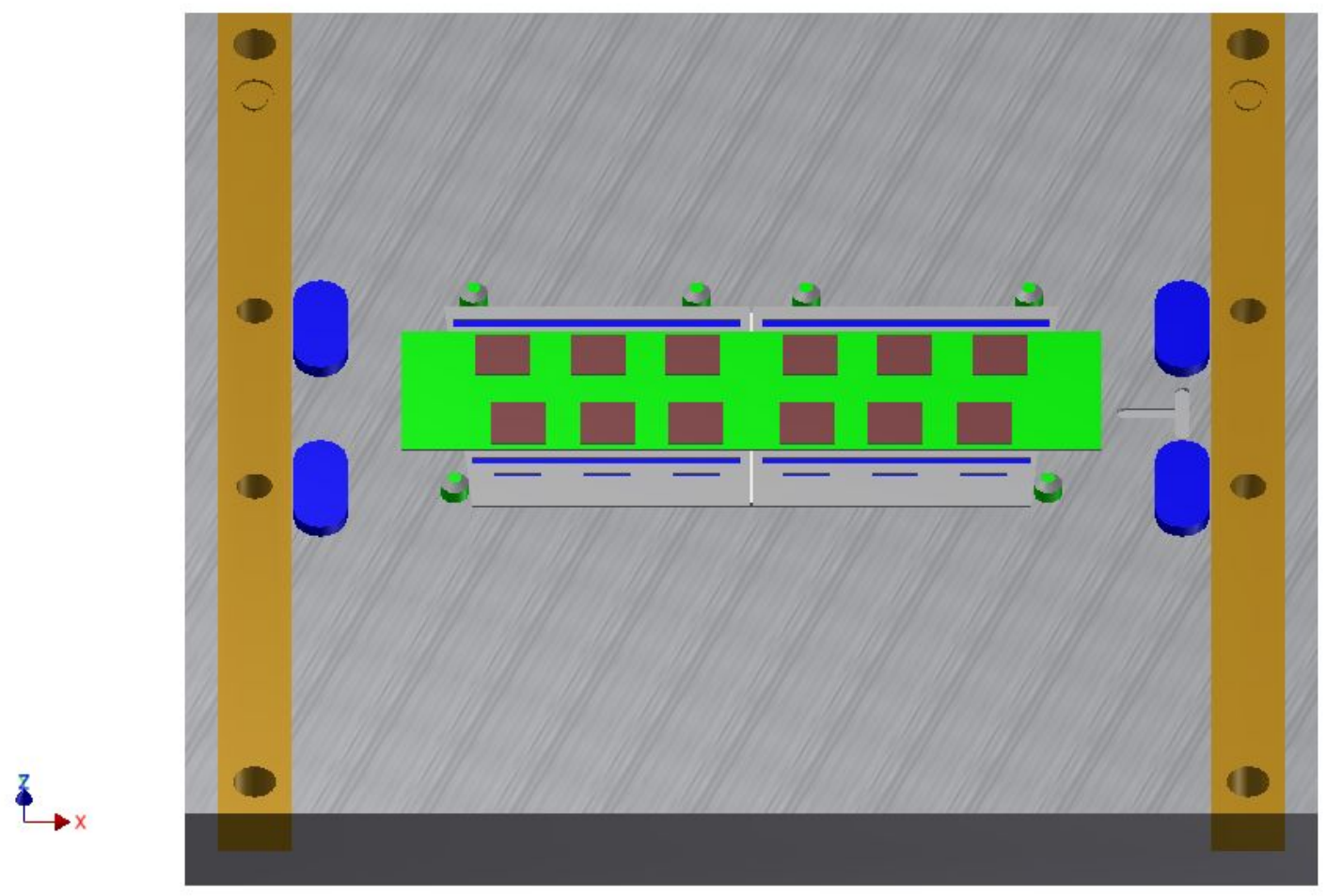

Design of tools for top sensors ("Bear" version)

- Sensors will be connected by one large hybrid 